\title{
Hydrogen-Bonding Effects on the Formation and Lifetimes of Charge-Separated States in Molecular Triads
}

\begin{tabular}{|r|l|}
\hline Journal: & The Journal of Physical Chemistry \\
\hline Manuscript ID: & jp-2012-02790j.R1 \\
\hline Manuscript Type: & Article \\
\hline Date Submitted by the Author: & 18 -Jun-2012 \\
\hline Complete List of Authors: & $\begin{array}{l}\text { Hankache, Jihane; University of Goettingen, Institute of Inorganic } \\
\text { Chemistry } \\
\text { Niemi, Marja; Tampere University of Technology, Department of Chemistry } \\
\text { and Bioengineering } \\
\text { Lemmetyinen, Helge; Tampere University of Technology, Department of } \\
\text { Environmental Technology } \\
\text { Wenger, Oliver; University of Goettingen, Institute of Inorganic Chemistry }\end{array}$ \\
\hline
\end{tabular}

SCHOLARONE $^{\text {M }}$

Manuscripts 


\title{
Hydrogen-Bonding Effects on the Formation and
}

\section{Lifetimes of Charge-Separated States in Molecular}

\author{
Triads \\ Jihane Hankache, ${ }^{\dagger}$ Marja Niemi, ${ }^{\ddagger}$ Helge Lemmetyinen, ${ }^{*}{ }^{\ddagger}$ and Oliver S. Wenger ${ }^{*}+$ \\ ${ }^{\dagger}$ Georg-August-Universität Göttingen, Institut für Anorganische Chemie, Tammannstrasse 4, D-37077 \\ Göttingen, Germany \\ ${ }^{\ddagger}$ Tampere University of Technology, Department of Chemistry and Bioengineering, P. O. Box 541, FIN- \\ 33101 Tampere, Finland \\ helge.lemmetyinen@tut.fi, oliver.wenger@chemie.uni-goettingen.de
}

RECEIVED DATE (to be automatically inserted after your manuscript is accepted if required according to the journal that you are submitting your paper to)

\begin{abstract}
Photoinduced electron transfer in two molecular triads comprised of a triarylamine donor, a $\mathrm{d}^{6}$ metal diimine photosensitizer, and a 9,10-anthraquinone acceptor was investigated with particular focus on the influence of hydrogen-bonding solvents on the electron transfer kinetics. Photoexcitation of the ruthenium(II) and osmium(II) sensitizers of these triads leads to charge-separated states containing an oxidized triarylamine unit and a reduced anthraquinone moiety. The kinetics for formation of these
\end{abstract}


charge-separated states were explored using femtosecond transient absorption spectroscopy. Strong hydrogen-bond donors such as hexafluoroisopropanol or trifluoroethanol cause a thermodynamic and kinetic stabilization of these charge-separated states which is attributed to hydrogen-bonding between alcoholic solvent and reduced anthraquinone. In the ruthenium triad this effect leads to a lengthening of the lifetime of the charge-separated state from $\sim 750 \mathrm{~ns}$ in dichloromethane to $\sim 3000$ ns in hexafluoroisopropanol while in the osmium triad the respective lifetime increases from $\sim 50$ ns to 2000 ns between the same two solvents. In both triads the lifetime of the charge-separated state correlates with the hydrogen-bond donor strength of the solvent but not with the solvent dielectric constant. These findings are relevant in the greater context of solar energy conversion in which one is interested in storing light energy in charge-separated states that are as long lived as possible. Furthermore they are relevant for understanding proton-coupled electron transfer (PCET) reactivity of electronically excited states at a fundamental level because changes in hydrogen-bonding strength accompanying changes in redox states may be regarded as an attenuated form of PCET.

\section{KEYWORDS}

Electron transfer, proton-coupled electron transfer, photochemistry, cyclic voltammetry, transient absorption

\section{INTRODUCTION}

Photoinduced electron transfer in molecular triads is of long-standing interest, and there are numerous investigations that report on molecular systems leading to long-lived charge-separated states after photoexcitation. $^{1-6}$ Consequently, one nowadays has a fairly clear idea what factors will lead to particularly long-lived charge-separated states from which one can potentially drive redox reactions that 
are thermodynamically uphill from electronic ground states. ${ }^{7-8}$ However, one aspect that has been comparatively little explored in molecular dyads and triads is the influence of hydrogen-bond donating solvents on the rates of photoinduced charge-separation and thermal charge-recombination. ${ }^{9-14}$ The influence of the dielectric constant of a solvent on electron transfer rates seems fairly well understood, ${ }^{15-}$ ${ }^{18}$ but we deemed it desirable to investigate specifically the importance of the hydrogen-bond donor property of a solvent. Recent (experimental and theoretical) investigations of proton-coupled electron transfer (PCET) have shown how important electron-proton coupling for the overall reaction rates can be. ${ }^{19-26}$ Against this background, we decided to explore to what extent electron transfer rates in carefully designed donor-sensitizer-acceptor triads would depend on the presence of hydrogen-bonding solvent. In a sense, changes in hydrogen-bonding strength that accompany photoinduced electron transfer represent an attenuated form of PCET: ${ }^{27}$ Instead of the transfer of a full proton there is merely a shift of some proton density in the course of redox chemistry, and hence one might expect electron transfer kinetics to depend on the hydrogen-bond donating ability of a solvent. ${ }^{9-12}$

Scheme 1. Molecular structure of the two triads investigated in this work.

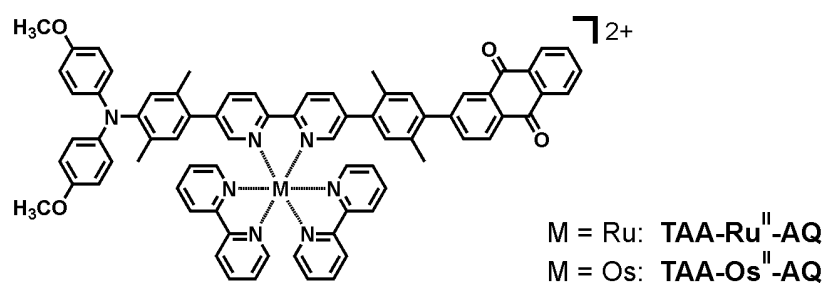

For our investigations we synthesized and characterized the two molecular triads shown in Scheme 1. They are both comprised of a triarylamine (TAA) electron donor, a $\mathrm{d}^{6}$ metal diimine photosensitizer, and a 9,10-anthraquinone (AQ) electron acceptor. The sensitizer is either a $\mathrm{Ru}(\mathrm{bpy})_{3}{ }^{2+}\left(\mathrm{bpy}=2,2^{\prime}-\right.$ bipyridine) or an $\mathrm{Os}(\mathrm{bpy})_{3}{ }^{2+}$ complex. The complete triads will be designated as TAA-Ru ${ }^{\text {II }}-\mathrm{AQ}$ and TAA-Os ${ }^{\text {II }}$-AQ throughout this paper. We previously reported on long-lived charge-separation in TAA$\mathrm{Ru}^{\mathrm{II}}-\mathrm{AQ}$ in acetonitrile, ${ }^{28}$ and recently we communicated the influence of the strong hydrogen-bond 
donor hexafluoroisopropanol (HFIP) on the lifetime of the charge-separated state $\left(\tau_{\mathrm{CR}}\right)$ in TAA-Os ${ }^{\mathrm{II}}$ AQ. ${ }^{29}$ Here, we present a significantly more detailed comparative study of both the ruthenium and osmium systems including a systematic investigation of $\tau_{\mathrm{CR}}$ as a function of hydrogen-bond donor strength of the solvent and as a function of temperature. In addition, we also report on the kinetics for charge-separation. The reason why electron transfer rates in our triads are susceptible to hydrogenbonding solvent is the presence of the anthraquinone electron acceptor which accepts hydrogen bonds both in its charge-neutral and in its one-electron reduced form, albeit with significantly different equilibrium constants. ${ }^{30-32}$ There have been numerous prior investigations of photoinduced electron transfer in dyads and triads with quinone acceptors, ${ }^{2,4,33-44}$ but the influence of hydrogen-bond donating solvents on the thermodynamics and kinetics for electron transfer in quinone systems has received very limited attention. ${ }^{9-11,14,45}$

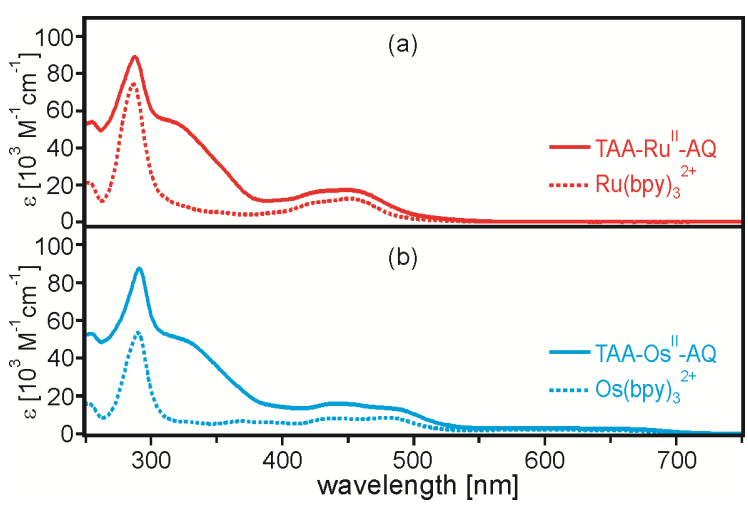

Figure 1. UV-Vis spectra of the TAA-Ru ${ }^{\text {II }}$-AQ (solid red trace) and TAA-Os ${ }^{\text {II }}$-AQ (solid blue trace) triads along with the UV-Vis spectra of Ru(bpy) ${ }_{3}{ }^{2+}$ (dashed red trace) and Os(bpy) ${ }_{3}{ }^{2+}$ (dashed blue trace) in $\mathrm{CH}_{3} \mathrm{CN}$.

\section{RESULTS AND DISCUSSION}

UV-Vis and luminescence spectroscopy. The solid lines in Figure 1 are the UV-Vis spectra of the two triads from Scheme 1 in acetonitrile at $25^{\circ} \mathrm{C}$. Comparison with the optical absorption spectra of the free 
$\mathrm{Ru}(\mathrm{bpy})_{3}{ }^{2+}$ and Os(bpy) ${ }_{3}{ }^{2+}$ complexes measured under identical conditions (dotted lines) shows that the two most prominent absorption bands of the triads are due to the photosensitizer: There is a bpylocalized $\pi-\pi^{*}$ absorption at $290 \mathrm{~nm}$ and a spin-allowed metal-to-ligand charge transfer (MLCT) band centered around $450 \mathrm{~nm} .{ }^{46}$ Both triads exhibit additional absorption between $300 \mathrm{~nm}$ and $370 \mathrm{~nm}$ which is due to the covalently attached AQ unit, ${ }^{28,44}$ while the TAA moiety contributes substantially to the absorption below $290 \mathrm{~nm} .^{28}$ The triad UV-Vis spectra are essentially a superposition of the absorption spectra of their individual molecular components and as such are indicative of electronically weakly coupled systems. The important difference between the ruthenium and osmium systems is the red-shift of the ${ }^{1}$ MLCT band in TAA-Os ${ }^{\text {II }}$-AQ with respect to TAA-Ru ${ }^{\text {II }}-\mathrm{AQ}$ and the exclusive observation of spin-forbidden ${ }^{3}$ MLCT transitions in the osmium triad above $550 \mathrm{~nm}^{47}$

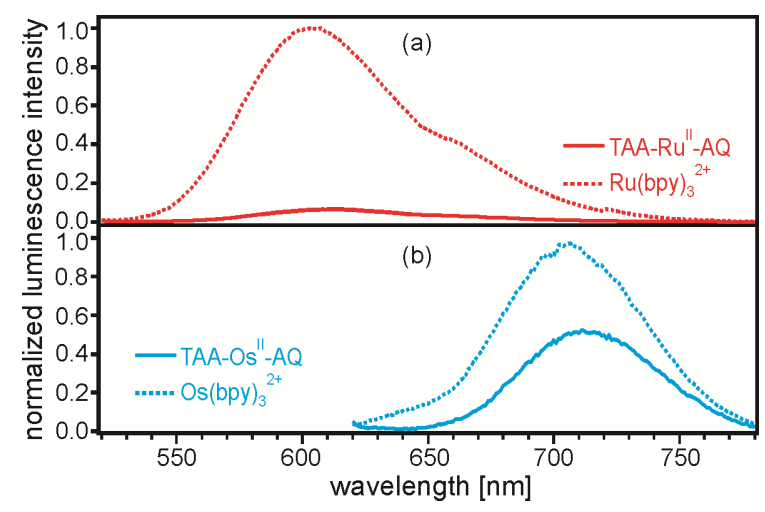

Figure 2. Luminescence spectra of the two triads from Scheme 1 in aerated $\mathrm{CH}_{3} \mathrm{CN}$ compared to those of $\mathrm{Ru}(\mathrm{bpy})_{3}{ }^{2+}$ and $\mathrm{Os}(\mathrm{bpy})_{3}{ }^{2+}$ measured under identical conditions. Excitation occurred at $450 \mathrm{~nm}$ in all cases, the intensities are normalized to a value of 1 at the band maxima of the reference complexes; differences in absorbance at the excitation wavelength were taken into account when normalizing.

Expectedly, the decrease in energy of the lowest-lying MLCT state between TAA-Ru ${ }^{\text {II }}$-AQ and TAAOs ${ }^{\text {II }}$ AQ also shows up in the luminescence spectra presented in Figure 2 (solid lines). These spectra were obtained from aerated $\mathrm{CH}_{3} \mathrm{CN}$ solutions after excitation into ${ }^{1} \mathrm{MLCT}$ bands at $450 \mathrm{~nm}$. Compared to the $\mathrm{Ru}(\mathrm{bpy})_{3}{ }^{2+}$ and $\mathrm{Os}(\mathrm{bpy})_{3}{ }^{2+}$ reference complexes (dotted lines) the triads exhibit significantly weaker emission, ${ }^{48}$ signaling the presence of an efficient nonradiative excited-state deactivation pathway 
in the triads. Compared to the osmium triad the ruthenium system exhibits substantially more luminescence quenching, suggesting that the abovementioned nonradiative excited-state deactivation pathway is more efficient in TAA-Ru ${ }^{\mathrm{II}}-\mathrm{AQ}$ than in TAA-Os ${ }^{\mathrm{II}}-\mathrm{AQ}$. The TAA and AQ units have their energetically lowest lying triplet excited states $3.2 \mathrm{eV}$ and $2.7 \mathrm{eV}$ above the electronic ground states. ${ }^{49-50}$ Given ${ }^{3} \mathrm{MLCT}$ energies of $2.12 \mathrm{eV}$ for $\mathrm{Ru}(\mathrm{bpy})_{3}{ }^{2+} 46$ and $1.79 \mathrm{eV}$ for $\mathrm{Os}(\mathrm{bpy})_{3}{ }^{2+}{ }^{51}$ luminescence quenching by triplet-triplet energy transfer is therefore thermodynamically improbable,${ }^{52-54}$ and indeed our prior investigations point to excited-state deactivation by electron transfer. ${ }^{28-29}$

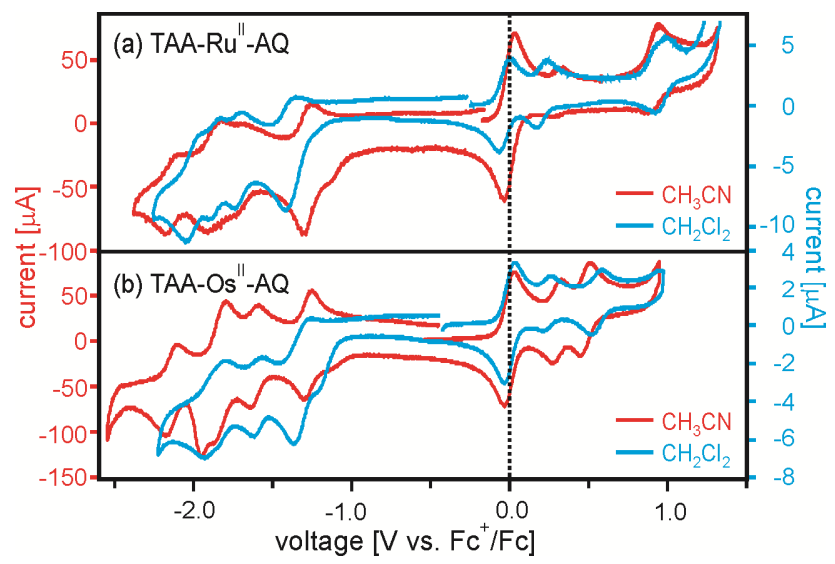

Figure 3. Cyclic voltammograms obtained from acetonitrile (red traces) and dichloromethane (blue traces) solutions of the TAA-Ru ${ }^{\text {II }}-\mathrm{AQ}$ (a) and TAA-Os ${ }^{\mathrm{II}}-\mathrm{AQ}$ (b) triads in presence of tetrabutylammonium hexafluorophosphate $\left(\mathrm{TBAPF}_{6}\right)$ electrolyte. The reversible waves at $0.0 \mathrm{~V}$ vs. $\mathrm{Fc}^{+} / \mathrm{Fc}$ (dashed vertical lines) are due to ferrocene $(\mathrm{Fc})$ which was added in small quantities for internal voltage calibration. The reduction potentials extracted from these voltammograms are summarized in Table 1.

Electrochemical investigations. Figure 3 shows the cyclic voltammograms measured on acetonitrile (red traces) and dichloromethane solutions (blue traces) of the two triads from Scheme 1 in presence of tetrabutylammonium hexafluorophosphate $\left(\mathrm{TBAPF}_{6}\right)$ electrolyte at $25^{\circ} \mathrm{C}$. The prominent reversible wave at $0.0 \mathrm{~V}$ vs. $\mathrm{Fc}^{+} / \mathrm{Fc}$ is due to ferrocene which was added in small quantities for internal voltage calibration. On the oxidative side of our voltammograms there is TAA oxidation near $0.3 \mathrm{~V}$ and a metal- 
based oxidation process near $0.9 \mathrm{~V}$ in the case of TAA- $\mathrm{Ru}^{\mathrm{II}}-\mathrm{AQ}^{46}$ and near $0.5 \mathrm{~V}$ in TAA-Os ${ }^{\mathrm{II}}-\mathrm{AQ} .^{51} \mathrm{On}$ the reductive side there is an AQ-localized reduction process near $-1.3 \mathrm{~V}^{44,55-56}$ and a series of up to three bpy-localized reductions between $-1.6 \mathrm{~V}$ and $-2.2 \mathrm{~V} \cdot{ }^{57-58}$ Most of the redox processes observed in Figure 3 are at least quasi-reversible, and the half-wave potentials extracted from this data are summarized in Table 1. We note that the key difference between the two triads is in the electrochemical potential for metal oxidation while all other redox potentials are nearly identical in both systems. The main difference between acetonitrile and dichloromethane solvent is that TAA oxidation occurs at more positive potentials in acetonitrile while AQ reduction requires more negative potentials in dichloromethane.

Table 1. Reduction potentials (in Volts vs. $\mathrm{Fc}^{+} / \mathrm{Fc}$ ) of the individual redox-active components of the two molecular triads from Scheme 1 in $\mathrm{CH}_{3} \mathrm{CN}$ and $\mathrm{CH}_{2} \mathrm{Cl}_{2}$ (extracted from the cyclic voltammograms in Figure 3). $0.1 \mathrm{M}$ tetrabutylammonium hexafluorophosphate $\left(\mathrm{TBAPF}_{6}\right)$ served as a supporting electrolyte.

\begin{tabular}{|l|c|c|c|c|}
\hline $\begin{array}{l}\text { redox } \\
\text { couple }\end{array}$ & $\begin{array}{c}\text { TAA-Ru } \\
\mathrm{CH}_{3} \mathrm{CN}\end{array}$ & $\begin{array}{c}\text { TAA-Au } \\
\mathrm{CH}_{2} \mathrm{Cl}_{2}\end{array}$ & $\begin{array}{c}\text { TAA-Os } \\
\mathrm{CH}_{3} \mathrm{CN}\end{array}$ & $\begin{array}{c}\text { TAA-Os } \\
\mathrm{CH}_{2} \mathrm{Cl}_{2}\end{array}$ \\
\hline $\mathrm{TAA}^{+/ 0}$ & 0.92 & 0.95 & 0.48 & 0.56 \\
\hline $\mathrm{AQ}^{0 /-}$ & -1.27 & -1.39 & -1.27 & -1.30 \\
\hline $\mathrm{bpy}^{0 /-}$ & -1.73 & -1.71 & -1.62 & -1.59 \\
\hline $\mathrm{bpy}^{0 /-}$ & -1.86 & -1.87 & -1.83 & -1.87 \\
\hline $\mathrm{bpy}^{0 /-}$ & -2.13 & -2.01 & -2.14 & N/A \\
\hline
\end{tabular}

Transient absorption spectroscopy. Panels (a) and (b) in Figure 4 display transient absorption spectra measured on deoxygenated solutions of the TAA-Ru ${ }^{\text {II }}-A Q$ and TAA-Os ${ }^{\text {II }}-A Q$ triads after excitation at $532 \mathrm{~nm}$ with laser pulses of $\sim 10 \mathrm{~ns}$ width. The spectra were obtained by averaging over a time window 
ranging from immediately after the laser pulse to $200 \mathrm{~ns}$ after the excitation pulse. In acetonitrile (red trace) and dichloromethane (blue trace) one observes transient absorption bands with maxima at $~ 380$ $\mathrm{nm}, \sim 570 \mathrm{~nm}$, and $770 \mathrm{~nm}$. Based on spectroelectrochemical investigations, the band at $770 \mathrm{~nm}$ can readily be assigned to the oxidized form of TAA (Figure 4c), while the bands at $380 \mathrm{~nm}$ and $570 \mathrm{~nm}$ can be attributed to the reduced AQ species (Figure 4d). Thus, the transient absorption spectra from Figure $4 \mathrm{a} / 4 \mathrm{~b}$ unambiguously show the spectral signature of a charge-separated state that may be designated as $\mathrm{TAA}^{+}-\mathrm{Ru}^{\mathrm{II}}-\mathrm{AQ}^{-}$and $\mathrm{TAA}^{+}-\mathrm{Os}^{\mathrm{II}}-\mathrm{AQ}^{-}{ }^{-28-29}$ As expected, the spectral fingerprint of this state is independent of the metal complex. The rates for formation and disappearance of the charge-separated state can be determined by monitoring the temporal evolution of the transient absorption signals at 380 , 570 , and $770 \mathrm{~nm}$.

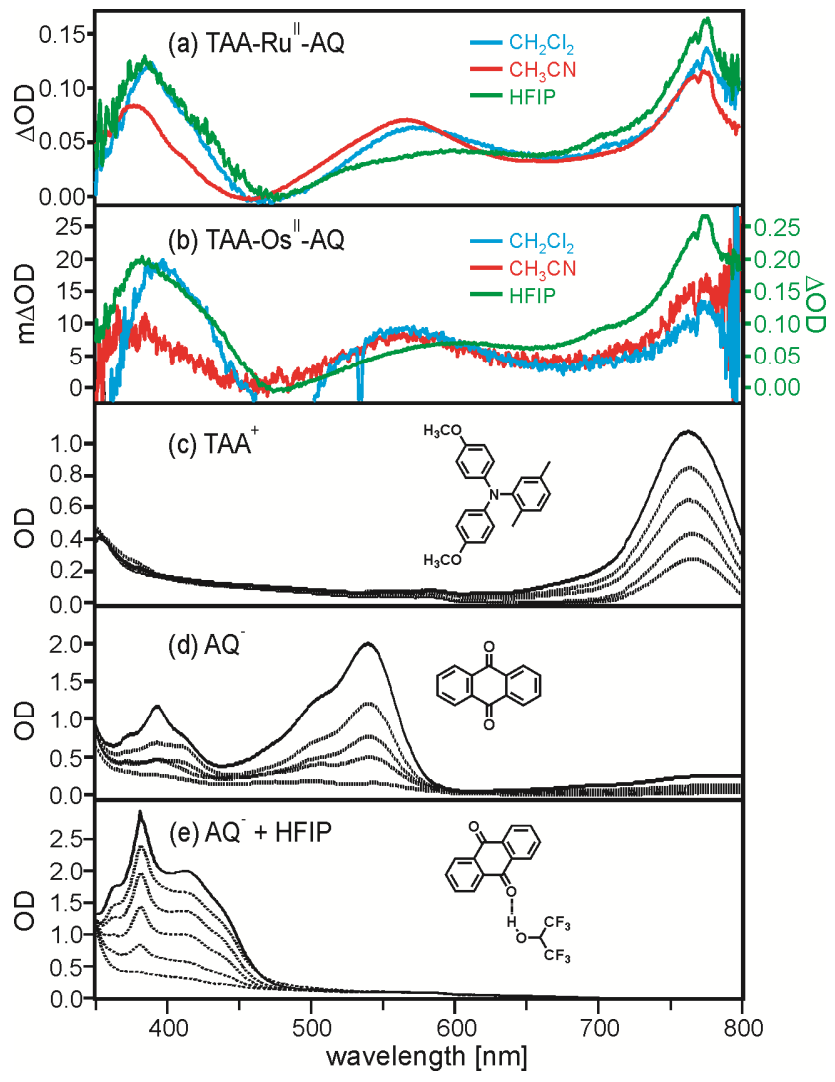

Figure 4. (a) Transient absorption spectra measured after excitation of TAA-Ru ${ }^{\mathrm{II}}-\mathrm{AQ}$ at $532 \mathrm{~nm}$ in three different deoxygenated solvents. Excitation pulse width was 10 ns, the spectra are time-integrated over 200 ns after the excitation pulse. (b) Transient absorption spectra obtained from analogous TAA-Os ${ }^{\text {II }}$ AQ solutions under identical conditions. (c) Spectroelectrochemical data obtained in the course of 
applying potentials more positive than $0.5 \mathrm{~V}$ vs. $\mathrm{Fc}^{+} / \mathrm{Fc}$ to a $\mathrm{CH}_{2} \mathrm{Cl}_{2}$ solution of the triarylamine molecule shown in the inset. (d) Spectroelectrochemical data obtained while applying potentials more negative than $-1.2 \mathrm{~V}$ vs. $\mathrm{Fc}^{+} / \mathrm{Fc}$ to a $\mathrm{CH}_{2} \mathrm{Cl}_{2}$ solution of 9,10-anthraquinone. (e) Spectroelectrochemistry of 9,10-anthraquinone in $\mathrm{CH}_{2} \mathrm{Cl}_{2}$ in presence of hexafluoroisopropanol. An electrochemical potential more negative than $-1.5 \mathrm{~V}$ vs. $\mathrm{Fc}^{+} / \mathrm{Fc}$ was applied for extended periods of time.

The data in Figure 5, acquired using a femtosecond pump-probe method, provides insight into the kinetics for the formation of the $\mathrm{TAA}^{+}-\mathrm{Ru}^{\mathrm{II}}-\mathrm{AQ}^{-}$state. Using a global fitting of decay curves in the spectral range from $500 \mathrm{~nm}$ to $790 \mathrm{~nm}$ (see Experimental Section for details) and plotting the amplitudes as a function of wavelength, so-called decay component spectra can be obtained.

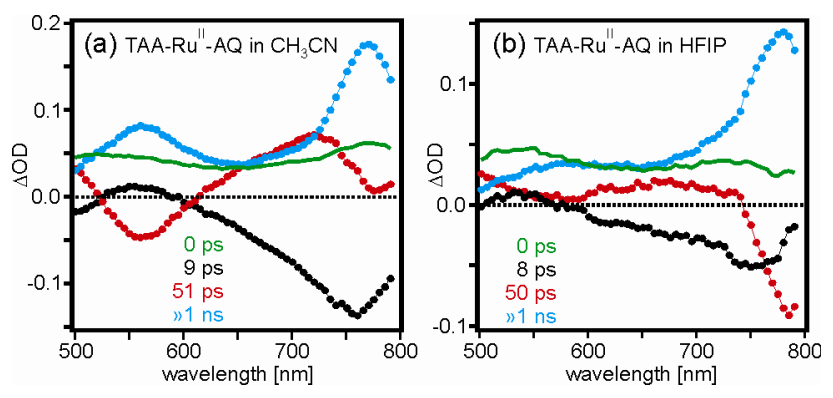

Figure 5. (a) Decay component spectra and calculated time-resolved spectrum at 0 ps obtained from global fits of decay curves measured after excitation of the ruthenium(II) triad at $420 \mathrm{~nm}$ in $\mathrm{CH}_{3} \mathrm{CN}$ with femtosecond laser pulses (see Experimental Section for details). (b) Analogous data obtained for the ruthenium(II) triad in HFIP.

The black trace in Figure 5a represents the 9-ps decay component of the ruthenium(II) triad in $\mathrm{CH}_{3} \mathrm{CN}$. Since there is essentially no ground-state absorption in the relevant spectral range, the decay component spectra of the ruthenium(II) triad are easy to read: Negative amplitudes correspond to rising absorption, while positive amplitudes represent absorption decays. Thus, the black trace in Figure 5a shows how the $\mathrm{TAA}^{+}$absorption at $770 \mathrm{~nm}$ rises. The formation of $\mathrm{AQ}^{-}$absorption at $550 \mathrm{~nm}$, by contrast, is only 
observed in the 50-ps decay component spectrum (red trace in Figure 5a). From this we conclude that the ${ }^{3}$ MLCT excited state of the $\mathrm{Ru}(\mathrm{bpy})_{3}{ }^{2+}$ photosensitizer in TAA-Ru ${ }^{\mathrm{II}}-\mathrm{AQ}$ is quenched reductively with a time constant of 9 ps. Subsequently, the $\mathrm{Ru}^{\mathrm{I}}$ complex transfers an electron to AQ with a time constant of 50 ps. The final decay component spectrum (blue trace in Figure 5a) is in good agreement with the red trace from Figure 4a, which was acquired using nanosecond equipment (note that in the femtosecond studies the instrumental time scale is limited to about 1 ns and thus no accurate lifetime can be given for the final component in Figure 5a).

When changing solvent from $\mathrm{CH}_{3} \mathrm{CN}$ to HFIP, the decay component spectra alter significantly (Figure 5b). The formation of the $\mathrm{TAA}^{+}$signal near $800 \mathrm{~nm}$ is now observable in the 50-ps decay component spectrum (red trace) while the 11-ps decay component spectrum (black trace) is more compatible with formation of hydrogen-bond perturbed $\mathrm{AQ}^{-}$(broad band between $450 \mathrm{~nm}$ and $750 \mathrm{~nm}$, see green trace in Figure $4 \mathrm{a}$ and discussion below). In other words, it appears that in HFIP the ${ }^{3}$ MLCT excited state of the $\mathrm{Ru}(\mathrm{bpy})_{3}{ }^{2+}$ photosensitizer is quenched oxidatively by (hydrogen-bonded) AQ with a time constant of 11 ps, followed by electron transfer from TAA to $\mathrm{Ru}(\mathrm{III})$ with a time constant of $50 \mathrm{ps}$. Again, even though the lifetime of the last decay component cannot be resolved in the pump-probe experiments, its spectrum (blue trace in Figure 5b) is in good agreement with the green trace from Figure 4a, which was acquired using nanosecond equipment.

The data in Figure 6 is helpful to elucidate the kinetics for formation of the charge-separated state in the osmium(II) triad. Unfortunately, the relevant kinetics are in the $1 \mathrm{~ns}-20 \mathrm{~ns}$ time regime for which neither the femtosecond nor nanosecond equipment is well suited, and hence the time constants given in the following are associated with significant experimental uncertainty. The green trace in Figure 6a shows the rise of the transient absorption at $550 \mathrm{~nm}$ after excitation of TAA-Os ${ }^{\mathrm{II}}-\mathrm{AQ}$ in $\mathrm{CH}_{3} \mathrm{CN}$ with laser pulse of $\sim 8 \mathrm{~ns}$ width. From this trace we learn that the $\mathrm{AQ}^{-}$signal in the osmium triad in $\mathrm{CH}_{3} \mathrm{CN}$ builds up with a time constant of $\sim 10 \mathrm{~ns}$. 


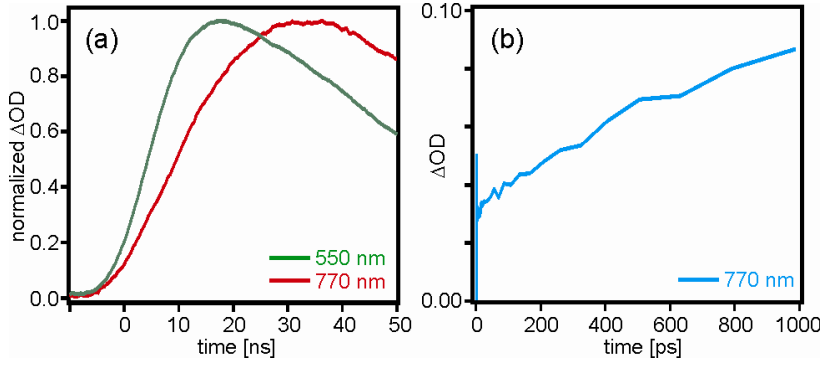

Figure 6. (a) Rise of the transient absorption signals at $550 \mathrm{~nm}$ (green trace) and $770 \mathrm{~nm}$ (red trace) after excitation of the TAA-Os ${ }^{\mathrm{II}}-\mathrm{AQ}$ triad at $532 \mathrm{~nm}$ with laser pulses of $\sim 8 \mathrm{~ns}$ width $\left(\mathrm{CH}_{3} \mathrm{CN}\right.$ solution). (b) Rise of the transient absorption signal at $770 \mathrm{~nm}$ after exciting the same triad at $420 \mathrm{~nm}$ with laser pulses of 200 fs duration (HFIP solution).

The red trace in Figure 6a monitors the build-up of $\mathrm{TAA}^{+}$at $770 \mathrm{~nm}$, and the associated time constant is $\sim 20 \mathrm{~ns}$. We conclude that the $\mathrm{TAA}^{+}-\mathrm{Os}^{\mathrm{II}}-\mathrm{AQ}^{-}$state in $\mathrm{CH}_{3} \mathrm{CN}$ is formed with a time constant on the order of $10 \mathrm{~ns}-20 \mathrm{~ns}$. The blue trace in Figure $6 \mathrm{~b}$ is the rise of the transient absorption signal of TAA ${ }^{+}$ in the osmium triad detected at $770 \mathrm{~nm}$ after femtosecond pulse excitation at $420 \mathrm{~nm}$. From this signal a time constant of $\sim 1 \mathrm{~ns}$ can be obtained for the formation of $\mathrm{TAA}^{+}$, but formation of $\mathrm{AQ}^{-}$could not be resolved in the pump-probe measurements. Given the experimental limitations, it seems reasonable to conclude that the $\mathrm{TAA}^{+}-\mathrm{Os}{ }^{\mathrm{II}}-\mathrm{AQ}^{-}$state in HFIP is formed with a time constant approaching $\sim 10 \mathrm{~ns}$.

Thus, the change in solvent between $\mathrm{CH}_{3} \mathrm{CN}$ and HFIP has a minor influence on the overall reaction rate for the formation of the $\mathrm{TAA}^{+}-\mathrm{Ru}^{\mathrm{II}}-\mathrm{AQ}^{-}$and $\mathrm{TAA}^{+}-\mathrm{Os}^{\mathrm{II}}-\mathrm{AQ}^{-}$states. However, in the ruthenium triad the reaction sequence changes from reductive excited-state quenching followed by $\mathrm{Ru}(\mathrm{III})$-to-AQ electron transfer in $\mathrm{CH}_{3} \mathrm{CN}$ to oxidative excited-state quenching followed by TAA-to- $\mathrm{Ru}(\mathrm{I})$ electron transfer in HFIP. 
With respect to disappearance of these charge-separated states via thermal charge recombination we note that our general experimental observation is that the optical densities at $380 \mathrm{~nm}, 570 \mathrm{~nm}$, and 770 nm exhibit single-exponential decays that are identical within experimental accuracy, i. e., lifetimes determined at the individual detection wavelengths typically differ by less than $10 \%$. This observation supports the notion of simultaneous disappearance of $\mathrm{TAA}^{+}$and $\mathrm{AQ}^{-}$in a single charge-recombination event. The actual experimental data, obtained from deoxygenated solutions at $25^{\circ} \mathrm{C}$, are shown in Figure S1 and Figure S2 (in the Supporting Information) which exhibit the decays at $770 \mathrm{~nm}$ (black traces for decay of $\mathrm{TAA}^{+}$) and $570 \mathrm{~nm}$ (green traces for decay of $\mathrm{AQ}^{-}$) for the TAA-Ru ${ }^{\mathrm{II}}-\mathrm{AQ}$ and TAA-Os ${ }^{\mathrm{II}}-\mathrm{AQ}$ molecules in 6 different solvents. The average charge-recombination lifetimes $\left(\tau_{\mathrm{CR}}\right)$ extracted from this data are listed in the last two columns of Table 2. The shortest lifetimes are measured in dichloromethane, to be specific 747 ns for TAA-Ru ${ }^{\text {II }}-A Q$ and 46 ns for TAA-Os ${ }^{\text {II }}-A Q$. The longest $\tau_{\mathrm{CR}}$ values are obtained for hexafluoroisopropanol, namely $3019 \mathrm{~ns}$ in the ruthenium triad and $1890 \mathrm{~ns}$ in the osmium system; these lifetimes are longer by factors of 4 and 41 , respectively, than those in dichloromethane.

Table 2. Gutmann acceptor numbers (AN), Reichardt parameters $\left(\mathrm{E}_{\mathrm{T}}{ }^{\mathrm{N}}\right)$, and dielectric constants $\left(\varepsilon_{\mathrm{r}}\right)$ of the solvents used in this study. Lifetimes of the TAA ${ }^{+}-\mathrm{M}^{\mathrm{II}}-\mathrm{AQ}^{-}$charge-separated states $\left(\tau_{\mathrm{CR}}\right)$ in these solvents at $25^{\circ} \mathrm{C}$ under deoxygenated conditions.

\begin{tabular}{|l|c|c|c|c|c|}
\hline solvent & AN & $\mathrm{E}_{\mathrm{T}}{ }^{\mathrm{N}}$ & $\varepsilon_{\mathrm{r}}$ & $\begin{array}{c}\tau_{\mathrm{CR}}[\mathrm{ns}] \\
\text { TAA-Ru }\end{array}$ & $\begin{array}{c}\tau_{\mathrm{CR}}[\mathrm{ns}] \\
\text { TAA-AQ }\end{array}$ \\
\hline hexafluoroisopropanol & 66.3 & 1.068 & 16.6 & 3019 & 1890 \\
\hline trifluoroethanol & 53.3 & 0.898 & 26.7 & 2870 & 692 \\
\hline Methanol & 41.3 & 0.762 & 32.66 & 2359 & 218 \\
\hline$n$-propanol & 33.5 & 0.617 & 20.45 & 1856 & 209 \\
\hline $\mathrm{CH}_{3} \mathrm{CN}$ & 18.9 & 0.460 & 35.94 & 1381 & 47 \\
\hline $\mathrm{CH}_{2} \mathrm{Cl}_{2}$ & 20.4 & 0.309 & 8.93 & 747 & 46 \\
\hline
\end{tabular}


Influence of solvent hydrogen-bond donor strength on $\tau_{\mathbf{C R}}$. Figure 7 a shows that there is a logarithmic correlation between the excited-state decay rate constant $\left(\mathrm{k}_{\mathrm{CR}}=\tau_{\mathrm{CR}}{ }^{-1}\right)$ and the Gutmann acceptor number (AN) of the solvents used for our lifetime measurements (Table 2). AN is a measure for the Lewis acidity of a solvent ${ }^{60}$ and may be interpreted as a measure for the hydrogen-bond donor strength when Lewis bases (such as the reduced anthraquinone moiety in the TAA ${ }^{+}-\mathrm{Ru}^{\mathrm{II}}-\mathrm{AQ}^{-}$and $\mathrm{TAA}^{+}-$ Os ${ }^{\mathrm{II}}-\mathrm{AQ}^{-}$states) are present. ${ }^{61}$ The Reichardt parameter $\left(\mathrm{E}_{\mathrm{T}}{ }^{\mathrm{N}}\right)$ represents an alternative measure of the Lewis acidity of a solvent, ${ }^{62-63}$ and the plot in Figure $7 \mathrm{~b}$ shows that there is a correlation between $\log \left(\mathrm{k}_{\mathrm{CR}}\right)$ and $\mathrm{E}_{\mathrm{T}}^{\mathrm{N}}$ similar to that observed in Figure 7a for the Gutmann acceptor number. By contrast, Figure 7c plotting $\log \left(\mathrm{k}_{\mathrm{CR}}\right)$ versus the solvent dielectric constant $\left(\varepsilon_{\mathrm{r}}\right)$ demonstrates that there is no obvious correlation between the lifetimes of the charge-separated states and $\varepsilon_{\mathrm{r}}$. Thus we conclude that it is predominantly the hydrogen-bond donating ability of a solvent which leads to a lengthening of $\tau_{\mathrm{CR}}$ in our triads. Even without the plots in Figure 7 the following simple consideration makes clear that hydrogen-bonding is more important than the dielectric constants of the solvent: When going from $\mathrm{CH}_{2} \mathrm{Cl}_{2}$ to $\mathrm{CH}_{3} \mathrm{CN} \varepsilon_{\mathrm{r}}$ increases from 8.93 to 35.94 , and $\tau_{\mathrm{CR}}$ increases by a factor of $\sim 1.7$ in both triads (Table 2). However, when replacing $\mathrm{CH}_{2} \mathrm{Cl}_{2}$ by HFIP $\varepsilon_{\mathrm{r}}$ increases only from 8.93 to 16.6 , but in this case $\tau_{\mathrm{CR}}$ increases by factors of 4 (in TAA-Ru ${ }^{\mathrm{II}}-\mathrm{AQ}$ ) and 41 (in TAA-Os ${ }^{\mathrm{II}}-\mathrm{AQ}$ ).

Our interpretation of the lifetime lengthening of the charge-separated state in presence of hydrogen-bond donating solvents makes sense in view of the fact that quinones are known to be good hydrogen-bond acceptors, particularly in their reduced forms. ${ }^{30-31,64}$ 

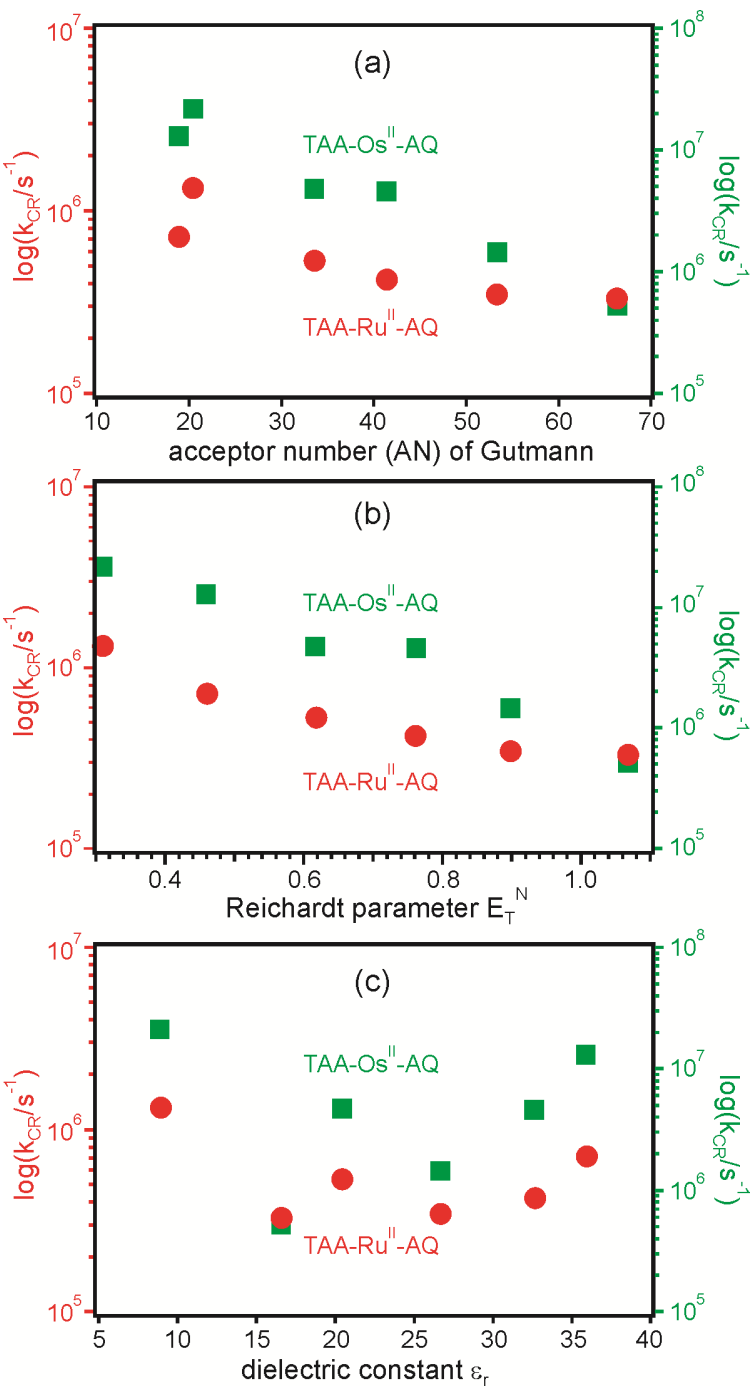

Figure 7. Dependence of the rate constant $\left(\mathrm{k}_{\mathrm{CR}}\right)$ for charge-recombination in TAA-Ru ${ }^{\mathrm{II}}-\mathrm{AQ}$ (red circles) and TAA-Os ${ }^{\mathrm{II}}$-AQ (green squares) on (a) Gutmann acceptor number, (b) Reichardt parameter, and (c) dielectric constant of the solvent. The $\mathrm{k}_{\mathrm{CR}}$ values were calculated from the lifetimes $\left(\mathrm{k}_{\mathrm{CR}}=\tau_{\mathrm{CR}}{ }^{-1}\right)$ in Table 2. 
(a) TAA-Ru"-AQ

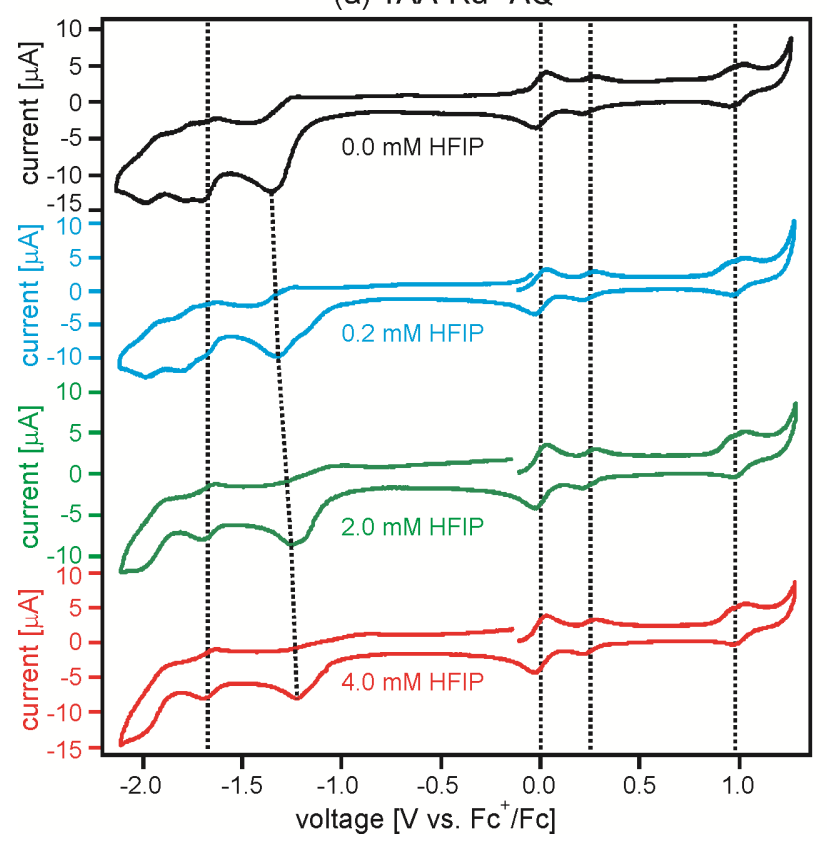

(b) TAA-Os"-AQ

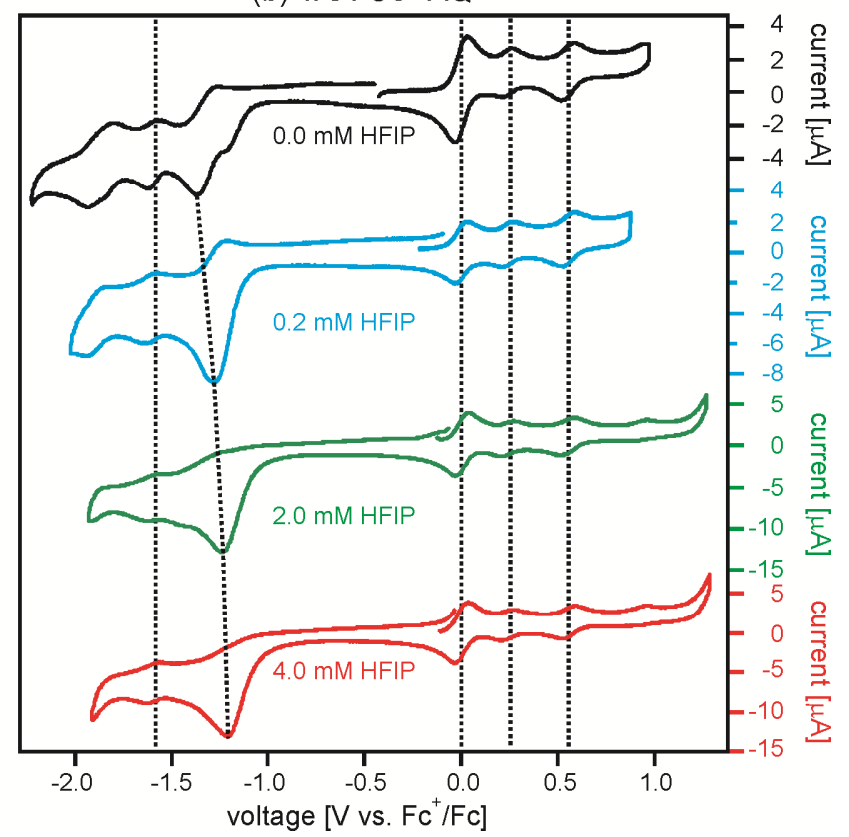

Figure 8. Cyclic voltammograms obtained from TAA-Ru ${ }^{\text {II }}-A Q$ (a) and TAA-Os ${ }^{\text {II }}-A Q$ (b) in dry and deoxygenated $\mathrm{CH}_{2} \mathrm{Cl}_{2}$ in presence of increasing concentrations of hexafluoroisopropanol (from top to bottom). The supporting electrolyte was $0.1 \mathrm{M} \mathrm{TBAPF}_{6}$, the waves at $0.0 \mathrm{~V}$ vs. $\mathrm{Fc}^{+} / \mathrm{Fc}$ are due to the ferrocene reference.

Influence of hydrogen-bonding on the $A Q / A^{-}$reduction potential. In order to probe what effect a strong hydrogen-bond donor may have on the thermodynamic stability of the $\mathrm{TAA}^{+}-\mathrm{Ru}^{\mathrm{II}}-\mathrm{AQ}^{-}$and $\mathrm{TAA}^{+}-\mathrm{Os}^{\mathrm{II}}-\mathrm{AQ}^{-}$charge-separated states it seemed necessary to perform electrochemical studies in HFIP. Since it is not possible to measure cyclic voltammograms in pure HFIP, we explored the effect of HFIP addition to dichloromethane solutions of our triads. Figure 8 shows the results of these experiments. The waves at $0 \mathrm{~V}$ vs. $\mathrm{Fc}^{+} / \mathrm{Fc}$ are due to the ferrocene reference substance, all other waves are due to the TAA-Ru ${ }^{\text {II }}$ AQ (left panel) and TAA-Os ${ }^{\text {II }}$-AQ molecules (right panel). We note that the TAA oxidation near $0.3 \mathrm{~V}$, the metal-based oxidations near $0.9 \mathrm{~V}\left(\mathrm{Ru}(\mathrm{bpy})_{3}{ }^{2+}\right.$ unit) and $0.6 \mathrm{~V}\left(\mathrm{Os}(\mathrm{bpy})_{3}{ }^{2+}\right.$ unit $)$, as well as the first bpy-localized reduction near $-1.7 \mathrm{~V}$ are all insensitive to HFIP addition (dotted vertical lines), at least up to a concentration of $4 \mathrm{mM}$. By contrast, the AQ-based reduction near $-1.3 \mathrm{~V}$ shifts to markedly less negative potentials with increasing HFIP concentration. This observation is similar to 
what has been previously reported for other benzoquinones in aprotic solvent upon addition of alcoholic solvents, ${ }^{14,30,65}$ and it is a manifestation of hydrogen-bonding between HFIP and anthraquinone monoanion. At millimolar HFIP concentrations there is likely to be a chemical equilibrium between hydrogen-bonded and non-hydrogen bonded species in solution:

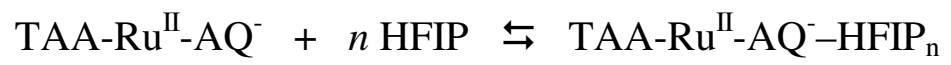

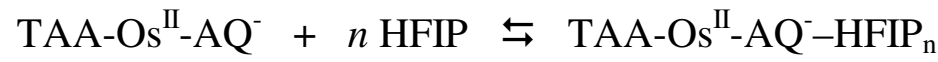

In equation $1 \mathrm{a}$ and $1 \mathrm{~b} n$ represents the number of HFIP molecules which are hydrogen-bonded to the reduced AQ unit. Gupta and Linschitz demonstrated that based on cyclic voltammetry hydrogenbonding equilibria such as those from equation $1 \mathrm{a} / 1 \mathrm{~b}$ can be evaluated quantitatively in the sense that equilibrium constants $\left(\mathrm{K}_{\mathrm{eq}}\right)$ can be determined. ${ }^{30,65}$ Specifically, based on equation $2 \mathrm{~K}_{\mathrm{eq}}$ can be obtained from plots of $\Delta \mathrm{E}_{\text {red }}$ versus $\log ([\mathrm{HFIP}])$, where $\Delta \mathrm{E}_{\text {red }}$ is the difference between the anthraquinone reduction potential at a given HFIP concentration ([HFIP]) and the respective potential in pure $\mathrm{CH}_{2} \mathrm{Cl}_{2} \cdot{ }^{30,65}$

$$
\Delta \mathrm{E}_{\mathrm{red}}=n \cdot 2.3 \cdot(R \cdot \mathrm{T} / F) \cdot \log ([\mathrm{HFIP}])+(R \cdot \mathrm{T} / F) \cdot \ln \left(\mathrm{K}_{\mathrm{eq}}\right)
$$

In equation $2 R$ is the gas constant, T is the temperature, and $F$ is the Faraday constant. The parameter $n$ is the abovementioned number of hydrogen-bonded HFIP molecules. Plots of $\Delta \mathrm{E}_{\text {red }}$ versus $\log ([\mathrm{HFIP}])$ are shown in Figure 9 for the ruthenium (circles) and osmium triads (squares). Experimental difficulties associated with the fact that AQ reduction becomes irreversible at higher concentrations (Figure 8) limit our investigation to only three data points, and hence the errors associated with our $\mathrm{K}_{\mathrm{eq}}$ estimates will be considerable. Linear regression fits to the two sets of data (dotted lines in Figure 9) have slopes of 0.061 $\mathrm{V}$ (ruthenium) and $0.045 \mathrm{~V}$ (osmium) which yields $n=1.0$ (TAA-Ru $\left.{ }^{\text {II }}-\mathrm{AQ}\right)$ and $n=0.8$ (TAA-Os $\left.{ }^{\text {II }}-\mathrm{AQ}\right)$, suggesting that one HFIP molecule binds to $\mathrm{AQ}^{-}$in both triads. From the intercepts $(0.266 \mathrm{~V}$ and 0.254 
$\mathrm{V}$, respectively) we determine $\mathrm{K}_{\mathrm{eq}}=3.2 \cdot 10^{4} \mathrm{M}^{-1}$ and $\mathrm{K}_{\mathrm{eq}}=2.0 \cdot 10^{4} \mathrm{M}^{-1}$ for the ruthenium and osmium triads, respectively. These are fairly large values, but it should be kept in mind that one is adding an extremely strong hydrogen-bond donor to an aprotic (and rather apolar) solution $\left(\mathrm{CH}_{2} \mathrm{Cl}_{2}\right)$ of a good hydrogen-bond acceptor (AQ-).

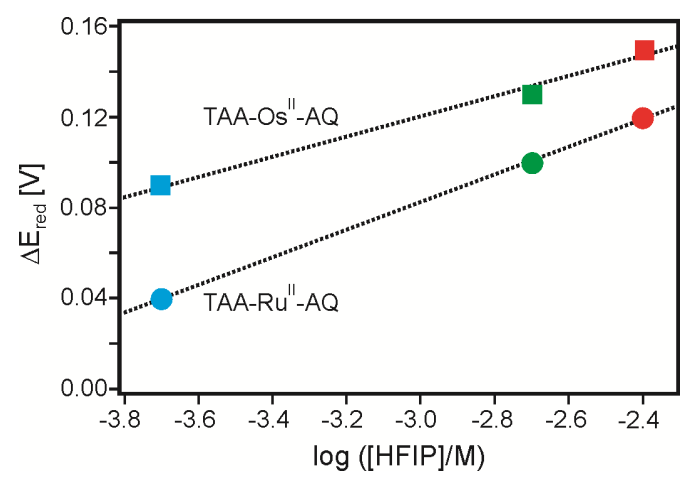

Figure 9. Shifts of the AQ/AQ- reduction potentials $\left(\Delta \mathrm{E}_{\text {red }}\right)$ in TAA-Ru ${ }^{\text {II }}-A Q$ (circles) and TAA-Os ${ }^{\text {II }}-A Q$ (squares) as a function of HFIP concentration in $\mathrm{CH}_{2} \mathrm{Cl}_{2}$. The color code corresponds to that used in Figure 8. The dotted straight lines are linear regression fits used for the determination of $\mathrm{K}_{\text {eq }}$ (eq. 2 ).

As mentioned above, the electrochemical potential for AQ reduction in pure HFIP cannot be measured directly. However, from the linear regression fits to the data in Figure 9 it is possible to extrapolate to $[$ HFIP $]=9.5 \mathrm{M}$ (i. e., the molarity of hexafluoroisopropanol in itself; $\log ([\mathrm{HFIP}]) \approx 1)$ in order to obtain at least a crude estimate for the shift of the AQ reduction potential $\left(\Delta \mathrm{E}_{\text {red }}\right)$ between $\mathrm{CH}_{2} \mathrm{Cl}_{2}$ and HFIP. This procedure yields $\Delta \mathrm{E}_{\text {red }} \approx 0.3 \mathrm{~V}$ for TAA-Ru ${ }^{\text {II }}-\mathrm{AQ}$ and TAA-Os ${ }^{\mathrm{II}}-\mathrm{AQ}$, but it should be kept in mind that this value represents a crude estimate at best. It may seem bold to make an extrapolation based on only three data points over such a large concentration range, but it is to be noted that the main shift in reduction potential occurs already at very low concentrations ( $0.15 \mathrm{~V}$ for TAA-Ru ${ }^{\mathrm{II}}-\mathrm{AQ}$ at $4 \mathrm{mM}$ HFIP), and it is the best that can be done in the present situation in order to obtain a least a very rough idea of $\Delta \mathrm{E}_{\text {red }}$ in HFIP. We tentatively conclude that the $\mathrm{TAA}^{+}-\mathrm{Ru}^{\mathrm{II}}-\mathrm{AQ}^{-}$and $\mathrm{TAA}^{+}-\mathrm{Os}^{\mathrm{II}}-\mathrm{AQ}^{-}$charge-separated states are stabilized energetically by $\sim 0.3 \mathrm{eV}$ when going from $\mathrm{CH}_{2} \mathrm{Cl}_{2}$ to $\mathrm{HFIP}$, but note that this value has large error bars. 
Protonation as an alternative to hydrogen-bonding. Hexafluoroisopropanol is a relatively strongly acidic solvent, its $\mathrm{pK}_{\mathrm{a}}$ value in dimethylsulfoxide is $17.9 .^{30}$ Therefore, we deemed it necessary to consider the possibility that $\mathrm{AQ}^{-}$is actually protonated by HFIP rather than just hydrogen-bonded. First we note that the conjugate acid of $\mathrm{AQ}^{-}$has a $\mathrm{pK}_{\mathrm{a}}$ value of 5.3 in DMSO ${ }^{55}$ Consequently, protonation of $\mathrm{AQ}^{-}$by HFIP appears thermodynamically unlikely even in dichloromethane or pure HFIP. Second we have made an attempt to observe the conjugate acid of $\mathrm{AQ}^{-}$in a spectroelectrochemical experiment in order to be able to search for spectral signatures of this species in the transient absorption data from Figure $4 \mathrm{a} / 4 \mathrm{~b}$. The result from our spectroelectrochemical investigation is shown in Figure $4 \mathrm{e}$. In this experiment we applied an electrochemical potential more negative than $-1.5 \mathrm{~V} \mathrm{vs}$. $\mathrm{Fc}^{+} / \mathrm{Fc}$ (for extended periods of time) to a dichloromethane solution of AQ in presence of a small amount of HFIP. Instead of the two bands at $380 \mathrm{~nm}$ and $570 \mathrm{~nm}$ observed in solutions of pure AQ without HFIP (Figure 4d) one now observes a relatively sharp peak at $375 \mathrm{~nm}$ and a broader band centered around $410 \mathrm{~nm}$. This is in fact the spectral signature of the $\mathrm{AQH}_{2}$ species, i. e., twofold reduced and twofold protonated AQ. ${ }^{55}$ Thus, in our spectroelectrochemical experiment we are unable to observe the monoanionic species. ${ }^{66}$ Instead the dianion is formed and protonation of this strongly basic species by HFIP is no surprise. ${ }^{55} \mathrm{We}$ are thus left with our thermodynamic argument based on the comparison of $\mathrm{pK}_{\mathrm{a}}$ values which speaks against the protonation of $\mathrm{AQ}^{-}$by HFIP.

We also point out that the transient absorption spectra obtained in HFIP solution (green traces in Figure 4a/4b) differ to a relatively minor extent from those obtained in $\mathrm{CH}_{2} \mathrm{Cl}_{2}$ (blue traces) and $\mathrm{CH}_{3} \mathrm{CN}$ (red traces): There is a shift of the 570-nm $\mathrm{AQ}^{-}$band to longer wavelengths and a small decrease of the intensity of this band, but these small changes seem incompatible with formation of protonated $\mathrm{AQ}^{-}$; they are more likely to be a manifestation of an $\mathrm{AQ}^{-}$species that is slightly perturbed by hydrogenbonding. We also note that two-electron reduction of $\mathrm{AQ}$ to $\mathrm{AQ}^{2-}$ followed by protonation is a probable event at an electrode in the spectroelectrochemical experiment presented in Figure $4 \mathrm{e},{ }^{67-69}$ but in the 
photochemical experiments presented in Figure $4 \mathrm{a} / 4 \mathrm{~b}$ our triads (present at $\sim 10^{-5} \mathrm{M}$ concentration) can only perform one-electron chemistry.

All other solvents used in this study have higher $\mathrm{pK}_{\mathrm{a}}$ values than HFIP, hence $\mathrm{AQ}^{-}$protonation in these cases is even less probable.

Influence of reaction free energy $\left(\Delta \mathbf{G}_{\mathbf{C R}}\right)$ on $\tau_{\mathbf{C R}}$. Based on the electrochemical potentials from Table 1 the energy level diagram in Scheme 2 can be established. In doing so we have neglected any effects arising from distance-dependent donor-acceptor interactions and have simply calculated energies for the individual states from differences in reduction potentials. ${ }^{70}$ To the very left of each half of this diagram is the long-lived ${ }^{3}$ MLCT excited state of the triads, designated as TAA-*Ru ${ }^{\text {II }}-\mathrm{AQ}(2.12 \mathrm{eV}$ above the ground state $)^{46}$ and TAA-*Os ${ }^{\mathrm{II}}-\mathrm{AQ}($ at $1.79 \mathrm{eV}){ }^{51}$ These excited states evolve towards the chargeseparated states with a hole on TAA and an electron on AQ (at $1.57 \mathrm{eV} / 1.58 \mathrm{eV}$ in $\mathrm{CH}_{3} \mathrm{CN}$ ). The reaction sequences and kinetics for the formation of the $\mathrm{TAA}^{+}-\mathrm{Ru}^{\mathrm{II}}-\mathrm{AQ}^{-}$and $\mathrm{TAA}^{+}-\mathrm{Os}^{\mathrm{II}}-\mathrm{AQ}^{-}$states in $\mathrm{CH}_{3} \mathrm{CN}$ and HFIP have been discussed above, and in Scheme 2 we merely recapitulate the time constants reported above. We note that the changeover in reaction sequence for photoinduced chargeseparation in the ruthenium(II) triad must have its origin in the energetic stabilization of the TAA-Ru ${ }^{\text {III }}$ $\mathrm{AQ}^{-}$state in HFIP relative to $\mathrm{CH}_{3} \mathrm{CN}$ or $\mathrm{CH}_{2} \mathrm{Cl}_{2}$ ( $\sim 0.3 \mathrm{eV}$ due to hydrogen-bonding, see above).

In the following we focus on the decays of the $\mathrm{TAA}^{+}-\mathrm{Ru}^{\mathrm{II}}-\mathrm{AQ}^{-}$and $\mathrm{TAA}^{+}-\mathrm{Os}^{\mathrm{II}}-\mathrm{AQ}^{-}$states. In this context there are two important messages from Scheme 2: (i) the free energies $\left(\Delta \mathrm{G}_{\mathrm{CR}}\right)$ for charge-recombination in $\mathrm{CH}_{3} \mathrm{CN}$ and $\mathrm{CH}_{2} \mathrm{Cl}_{2}$ are virtually identical, yet $\tau_{\mathrm{CR}}$ is roughly a factor of 1.7 longer in acetonitrile for both triads; (ii) based on our $\Delta \mathrm{E}_{\text {red }}$ estimate extracted from the electrochemical data in Figure 9 and Figure $8(\sim 0.3 \mathrm{eV})$ the energetics for charge-recombination in HFIP are markedly different than in $\mathrm{CH}_{3} \mathrm{CN}$ and $\mathrm{CH}_{2} \mathrm{Cl}_{2}$, and this is accompanied by an increase of $\tau_{\mathrm{CR}}$ by factors of 4 (ruthenium triad) and 41 (osmium triad) relative to $\mathrm{CH}_{2} \mathrm{Cl}_{2}$. From this latter observation it appears plausible to conclude that a decrease in driving-force plays an important role for decelerating thermal charge-recombination in our 
triads. The difference between $\tau_{\mathrm{CR}}$ in acetonitrile and dichloromethane suggests that solvent dielectric constant does play some role, although clearly a less important one (see above).

Scheme 2. Energy level scheme showing the relevant emissive ${ }^{3}$ MLCT states (TAA-*Ru ${ }^{\text {II }}$-AQ and TAA-*Os ${ }^{\mathrm{II}}-\mathrm{AQ}$ ) along with all relevant charge-separated states of our triads in three different solvents. The energies of the charge-separated states in $\mathrm{CH}_{3} \mathrm{CN}$ and $\mathrm{CH}_{2} \mathrm{Cl}_{2}$ were estimated based on the cyclic voltammetry data in Table 1 and Figure 3 (see text). In HFIP, all states containing AQ- are assumed to be lowered in energy by $0.3 \mathrm{eV}$ relative to the energies estimated for $\mathrm{CH}_{2} \mathrm{Cl}_{2}$ (see text). Although energy values with two digits are indicated, we note that the error of these estimates is typically on the order of $0.1 \mathrm{eV}$.

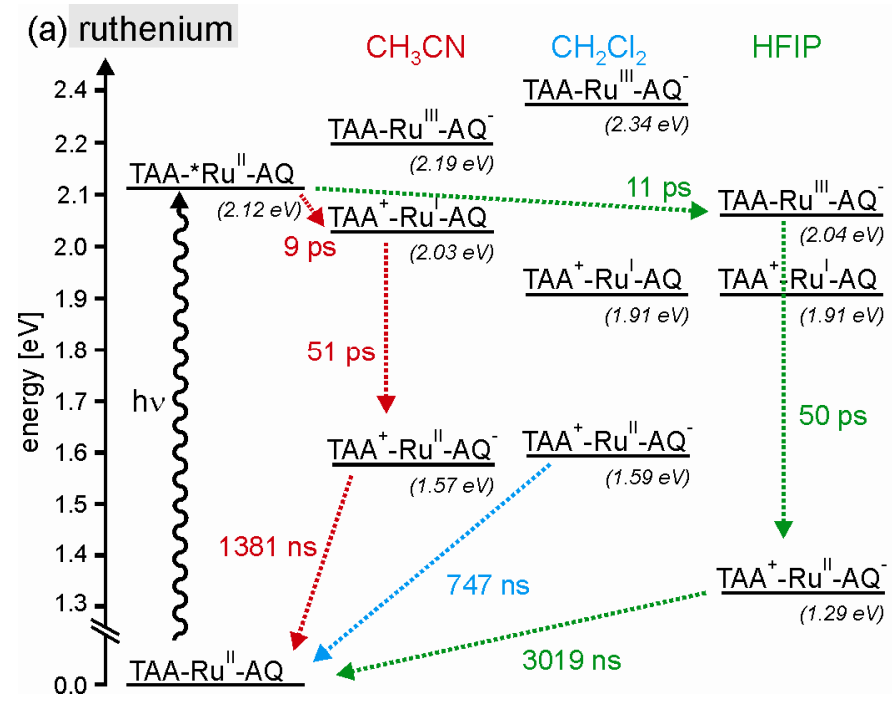

(b) osmium
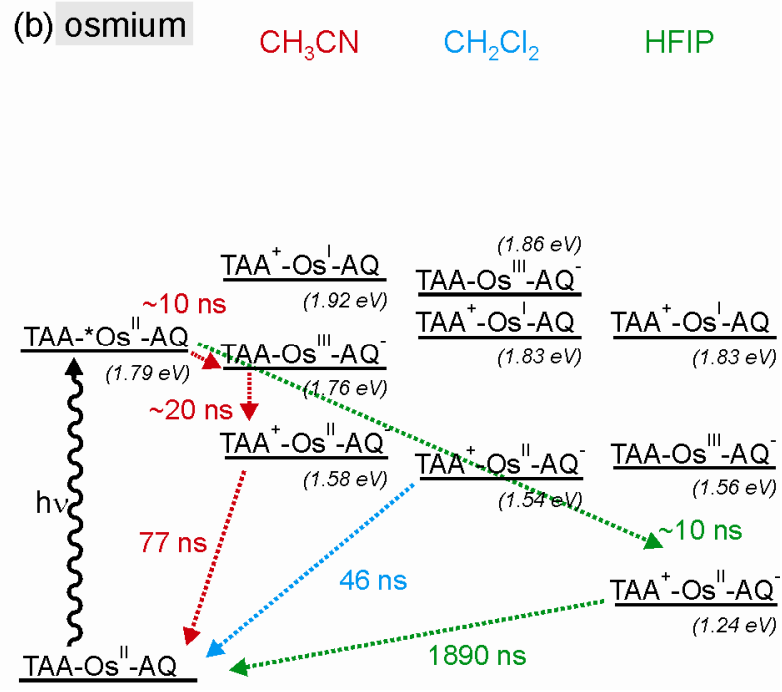

Activation energies for charge-recombination. Prior experimental studies on electron transfer in hydrogen-bonded systems have come to the conclusion that hydrogen-bond formation and breakage can contribute substantially to the reorganization energy $(\lambda)$ accompanying the electron transfer event. ${ }^{71-74}$ Therefore we explored the temperature dependence of $\tau_{\mathrm{CR}}$ in order to obtain information about the activation energies $\left(E_{A}\right)$ for thermal charge-recombination. Figure 10 shows Arrhenius plots based on lifetime measurements in $\mathrm{CH}_{3} \mathrm{CN}$ between $5^{\circ} \mathrm{C}$ and $70^{\circ} \mathrm{C}$ (Figure $\mathrm{S} 3$ for TAA-Ru ${ }^{\mathrm{II}}$-AQ; Figure $\mathrm{S} 4$ for TAA-Os ${ }^{\mathrm{II}}-\mathrm{AQ}$ ) and in HFIP between $5^{\circ} \mathrm{C}$ and $50^{\circ} \mathrm{C}$ (Figure S5 for TAA-Ru ${ }^{\mathrm{II}}-\mathrm{AQ}$; Figure S6 for TAA- 
Os $\left.{ }^{\mathrm{II}}-\mathrm{AQ}\right)$. The temperature of $5^{\circ} \mathrm{C}$ is the lower limit of what is possible in our experimental setup, hence no analogous measurements were performed with $\mathrm{CH}_{2} \mathrm{Cl}_{2}$ due to the small temperature range available for this solvent $\left(5^{\circ}-35^{\circ} \mathrm{C}\right)$. From the slopes of linear regression fits to the experimental data in Figure 10 we determine activation energies of $208 \mathrm{~cm}^{-1}(0.026 \mathrm{eV})$ for charge-recombination in TAA-Ru - AQ in $\mathrm{CH}_{3} \mathrm{CN}$ and $302 \mathrm{~cm}^{-1}(0.037 \mathrm{eV})$ for the same triad in HFIP. Thus, it appears that hydrogen-bonding does indeed affect the reorganization energy associated with charge-recombination, at least in the ruthenium triad. By contrast, for the osmium triad $\mathrm{E}_{\mathrm{A}}$ we obtain $797 \mathrm{~cm}^{-1}(0.099 \mathrm{eV})$ in $\mathrm{CH}_{3} \mathrm{CN}$ and 757 $\mathrm{cm}^{-1}(0.094 \mathrm{eV})$ in HFIP, i. e., the activation energy stays unchanged within experimental accuracy.

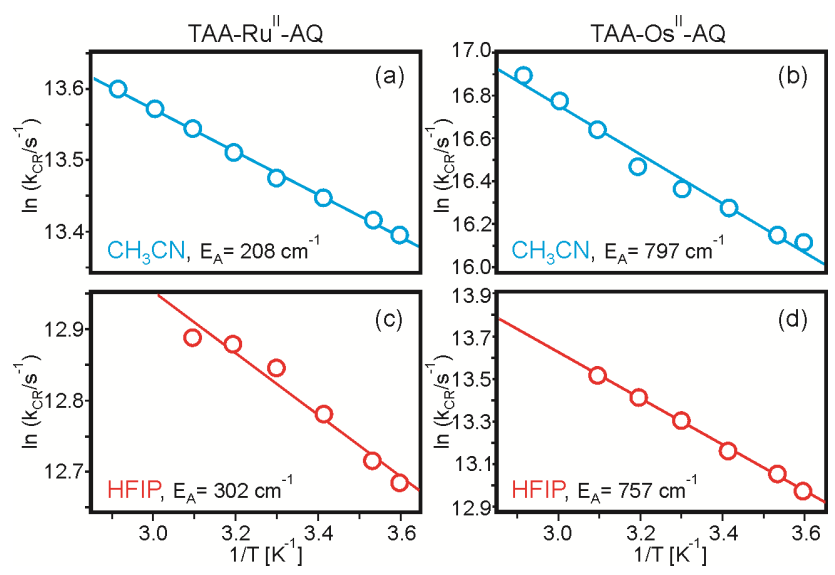

Figure 10. Arrhenius plots based on charge-recombination rates observed for the TAA-Ru ${ }^{\mathrm{II}}-\mathrm{AQ}$ (left) and TAA-Os ${ }^{\mathrm{II}}-\mathrm{AQ}$ (right) triads in deoxygenated $\mathrm{CH}_{3} \mathrm{CN}$ (upper panels) and HFIP (lower panels). The experimental transient absorption decays (obtained after excitation at $532 \mathrm{~nm}$, detected at $570 \mathrm{~nm}$ and $770 \mathrm{~nm}$ ) are shown in Figure S3 - Figure S6 of the Supporting Information.

Differences in $\mathbf{E}_{\mathrm{A}}$ and $\tau_{\mathrm{CR}}$ between ruthenium and osmium triads. The finding of chargerecombination activation energies which are about a factor of 4 larger in the osmium triad than in the ruthenium system is somewhat peculiar. The reactants involved in this process are the same in both triads, namely the organic $\mathrm{TAA}^{+}$and $\mathrm{AQ}^{-}$moieties, while in first approximation the metal could be expected to play a subordinate role for charge-recombination. The experimental data suggests that this is not the case; it does indeed matter whether a $\mathrm{Ru}(\mathrm{bpy})_{3}{ }^{2+}$ or $\mathrm{Os}(\mathrm{bpy})_{3}{ }^{2+}$ metal complex is present. Not 
only are the activation energies significantly different between the two triads, but also the lifetimes of their charge-separated states vary substantially: Although $\tau_{\mathrm{CR}}$ is on the same order of magnitude for TAA-Ru ${ }^{\text {II }}$-AQ and TAA-Os ${ }^{\text {II }}$-AQ in HFIP (3019 ns vs. 1890 ns, Table 2), in $\mathrm{CH}_{3} \mathrm{CN}$ and $\mathrm{CH}_{2} \mathrm{Cl}_{2} \tau_{\mathrm{CR}}$ differs by more than an order of magnitude between the ruthenium and osmium triads (e. g. 1381 ns vs. $77 \mathrm{~ns}$ in $\mathrm{CH}_{3} \mathrm{CN}$, Table 2). This observation combined with the finding of significantly different activation energies may suggest that charge-recombination in the ruthenium and osmium triads proceeds through fundamentally different reaction channels with different rate-determining steps. It appears that the attempt to rationalize our $\tau_{\mathrm{CR}}$-values in terms of changes in driving-force and reorganization energies is somewhat simplistic. As pointed out by a reviewer, electronic factors such as different superexchange pathways as well as spin-orbit coupling may play a non-negligible role in our systems as well, but these factors are not at all easy to address experimentally. ${ }^{88}$

\section{SUMMARY AND CONCLUSIONS}

Hydrogen-bond donating solvents are found to have a strong impact on the lifetimes of photoproduced charge-separated states $\left(\tau_{\mathrm{CR}}\right)$ in molecular triads with anthraquinone electron acceptors. There is a correlation between $\tau_{\mathrm{CR}}$ and the hydrogen-bond donor strength of the solvent, while the dielectric constant of the solvent plays a smaller role. Electrochemical investigations lead us to the conclusion that charge-separated states with reduced anthraquinone are stabilized thermodynamically by roughly $0.3 \mathrm{eV}$ when going from $\mathrm{CH}_{2} \mathrm{Cl}_{2}$ to HFIP due to the formation of tightly hydrogen-bonded adducts between $\mathrm{AQ}^{-}$ and HFIP. In the ruthenium triad this leads to a changeover in reaction mechanism when going from $\mathrm{CH}_{3} \mathrm{CN}$ to HFIP solvent: In acetonitrile, there is first electron transfer from TAA to photoexcited $\mathrm{Ru}(\mathrm{bpy})_{3}{ }^{2+}$, followed by electron transfer from $\mathrm{Ru}(\mathrm{I})$ to AQ. In HFIP, the AQ moiety is reduced first because of the energetic stabilization of the TAA-Ru ${ }^{\text {III }}-\mathrm{AQ}^{-}$state. However, the overall kinetics for formation of the charge-separated states are not accelerated to significant extents by changing from $\mathrm{CH}_{3} \mathrm{CN}$ to HFIP, neither in the ruthenium(II) nor in the osmium(II) triad. 
Given the energetic stabilization of the TAA ${ }^{+}-\mathrm{M}^{\mathrm{II}}-\mathrm{AQ}^{-}$states in HFIP relative to $\mathrm{CH}_{3} \mathrm{CN}$ or $\mathrm{CH}_{2} \mathrm{Cl}_{2}$ (Scheme 2), there is less driving-force for charge-recombination in HFIP, and we propose that this is an important reason for the lifetime lengthening observed between $\mathrm{CH}_{2} \mathrm{Cl}_{2}$ and $\mathrm{HFIP}$. The activation energies for charge recombination in our molecules are similar in aprotic solvent and HFIP, but they differ markedly between the ruthenium and osmium triads. There is also an order-of-magnitude difference in $\tau_{\mathrm{CR}}$ between TAA-Ru ${ }^{\mathrm{II}}-\mathrm{AQ}$ and TAA-Os ${ }^{\mathrm{II}}-\mathrm{AQ}$ in aprotic solvent which, combined with the finding of significantly different activation energies for charge-recombination, may hint at fundamentally different recombination pathways in the two triads, but this remains a rather speculative point.

In conclusion we note that hydrogen-bonding can stabilize photoproduced charge-separated states in artificial quinone triads thermodynamically and kinetically, and this may be of interest for obtaining long-lived charge-separated states in a variety of different molecular systems. ${ }^{76}$ Hydrogen-bonding effects may thus be exploited in artificial systems in a similar way as in bacterial photosynthesis where differences in hydrogen-bonding strengths between amino acid side chains and the $\mathrm{Q}_{\mathrm{A}}$ and $\mathrm{Q}_{\mathrm{B}}$ primary and secondary electron acceptors are co-responsible for fine-tuning of the redox potentials and electron transfer kinetics. ${ }^{77-80}$

Hydrogen-bond formation may be regarded a preceding step to proton transfer, ${ }^{27}$ and hence one might expect to observe even stronger effects in systems in which the electron acceptor can indeed be protonated and not just hydrogen-bonded. Investigation of suitable molecular systems which exhibit such photoinduced proton-coupled electron transfer (PCET) chemistry capable of stabilizing chargeseparated states appears therefore highly attractive. ${ }^{9,14,26,81-86}$ 


\section{EXPERIMENTAL SECTION}

The synthetic procedures which were used to obtain the triads from Scheme 1 were described in detail in the Supporting Information to our prior communications, product characterization data including results from ${ }^{1} \mathrm{H}$ NMR spectroscopy, high-resolution mass spectrometry, and elemental analysis can also be found there. ${ }^{28-29}$ UV-Vis spectra were recorded on a Cary 300 instrument from Varian, steady-state luminescence spectra were measured on a Fluorolog-322 instrument from Horiba Jobin-Yvon equipped with a TBC-07C detection module from Hamamatsu. Cyclic voltammetry was conducted using a Versastat3-200 potentiostat from Princeton Applied Research and a platinum disk working electrode. Two silver wires served as counter and quasi-reference electrodes, dry solutions were deoxygenated by bubbling nitrogen gas prior to voltammetry sweeps at rates of $100 \mathrm{mV} / \mathrm{s}$. For spectroelectrochemistry an optically transparent thin layer (OTTLE) cell from Specac ${ }^{87}$ was placed in the Cary 300 instrument, and the electrochemical potential was applied using the potentiostat mentioned above. Transient absorption was measured on a LP920-KS spectrometer from Edinburgh Instruments, equipped with an iCCD camera from Andor and a photomultiplier tube for recording time profiles at a given wavelength. Excitation occurred with the frequency-doubled output from a Quantel Brilliant b laser. For the $\tau_{\mathrm{CR}}$ measurements samples were thoroughly deoxygenated either by bubbling nitrogen gas or by subjecting the samples to three subsequent freeze-pump-thaw cycles in home-built quartz cuvettes. Temperature control in the activation energy experiments occurred with a TC-125 instrument from Quantum Northwest. A pump-probe method for time-resolved absorption was used to detect the fast processes with a time resolution of $150 \mathrm{fs}$. The femtosecond pulse generator (TISSA50, Avesta/CDP) was pumped with a continuous wave Nd:YAG second harmonic laser (Verdi-V6, Coherent). The femtosecond pulses were amplified with a Ti-Sapphire amplifier (Avesta/CDP) pumped by a Nd:YAG laser (LF114, Solar TII). After the amplifier the beam was split in two. The first part was passed through a second harmonic generator to obtain excitation (pump) pulses at $420 \mathrm{~nm}$, and the second part through a water cuvette to generate a white continuum as the monitoring (probe) pulse. The excitation beam was directed to a delay 
line (Avesta/CDP) enabling measurements of the transient absorption spectra up to $1 \mathrm{~ns}$ after excitation. A monochromator (Andor 0032) and a CCD camera (Newton DU920N-BR-DD, Andor) were used to record the spectra. The sample was placed in a rotating cuvette to prevent degradation due to the laser excitation. The obtained time-resolved absorption decay curves were globally fitted to a sum of exponentials:

$$
\Delta \mathrm{OD}(\lambda, t)=\Sigma a_{\mathrm{i}}(\lambda) \cdot \exp \left(-t / \tau_{\mathrm{i}}\right)
$$

In equation $3, a_{\mathrm{i}}$ are the amplitudes and $\tau_{\mathrm{i}}$ are the lifetimes of the components. The decay component spectra are obtained when the amplitudes of individual components are plotted as a function of wavelength $(\lambda)$. Using the lifetimes and amplitudes provided by the fitting, it is possible to calculate the time-resolved spectrum at any given time $(t)$ from eq. 3 . The 0 ps spectra in Figure 5 were calculated from eq. 3 with $t=0$.

\section{ACKNOWLEDGMENT}

Research grants from the Deutsche Forschungsgemeinschaft (INST186/872-1 and WE4815/1-1) and from the Finnish Academy are gratefully acknowledged.

\section{ASSOCIATED CONTENT}

Additional transient absorption data showing the decays from which the $\tau_{\mathrm{CR}}$ values in Table 2/Figure 7 and the activation energies $\left(\mathrm{E}_{\mathrm{A}}\right)$ in Figure 10 were extracted. This materials is available free of charge via the Internet at http://pubs.acs.org. 


\section{REFERENCES}

(1) Collin, J.-P.; Guillerez, S.; Sauvage, J.-P.; Barigelletti, F.; Flamigni, L.; De Cola, L.; Balzani, V., Coord. Chem. Rev. 1991, 111, 291-296.

(2) Wasielewski, M. R., Chem. Rev. 1992, 92, 435-461.

(3) Sauvage, J.-P.; Collin, J.-P.; Chambron, J.-C.; Guillerez, S.; Coudret, C.; Balzani, V.; Barigelletti, F.; De Cola, L.; Flamigni, L., Chem. Rev. 1994, 94, 993-1019.

(4) Balzani, V., Electron transfer in chemistry. VCH Wiley: Weinheim, 2001; Vol. 3.

(5) Baranoff, E.; Collin, J.-P.; Flamigni, L.; Sauvage, J.-P., Chem. Soc. Rev. 2004, 33, 147-155.

(6) Magnuson, A.; Anderlund, M.; Johansson, O.; Lindblad, P.; Lomoth, R.; Polivka, T.; Ott, S.; Stensjö, K.; Styring, S.; Sundström, V.; Hammarström, L., Acc. Chem. Res. 2009, 42, 1899-1909.

(7) Meyer, T. J., Acc. Chem. Res. 1989, 22, 163-170.

(8) Alstrum-Acevedo, J. H.; Brennaman, M. K.; Meyer, T. J., Inorg. Chem. 2005, 44, 6802-6827.

(9) Hung, S. C.; Macpherson, A. N.; Lin, S.; Liddell, P. A.; Seely, G. R.; Moore, A. L.; Moore, T. A.; Gust, D., J. Am. Chem. Soc. 1995, 117, 1657-1658.

(10) Kawai, K.; Osakada, Y.; Takada, T.; Fujitsuka, M.; Majima, T., J. Am. Chem. Soc. 2004, 126, 12843-12846.

(11) Okamoto, K.; Fukuzumi, S., J. Phys. Chem. B 2005, 109, 7713-7723.

(12) Fukuzumi, S.; Okamoto, K.; Yoshida, Y.; Imahori, H.; Araki, Y.; Ito, O., J. Am. Chem. Soc. 2003, 125, 1007-1013. 
(13) Fukuzumi, S.; Yoshida, Y.; Okamoto, K.; Imahori, H.; Araki, Y.; Ito, O., J. Am. Chem. Soc. 2002, 124, 6794-6795.

(14) Hankache, J.; Hanss, D.; Wenger, O. S., J. Phys. Chem. A 2012, doi: 10.1021/jp300090n.

(15) Marcus, R. A.; Sutin, N., Biochim. Biophys. Acta 1985, 811, 265-322.

(16) Newton, M. D., Chem. Rev. 1991, 91, 767-792.

(17) Liu, Y. P.; Newton, M. D., J. Phys. Chem. 1994, 98, 7162-7169.

(18) Morandeira, A.; Fürstenberg, A.; Gumy, J. C.; Vauthey, E., J. Phys. Chem. A 2003, 107, 53755383.

(19) Mayer, J. M., Annu. Rev. Phys. Chem. 2004, 55, 363-390.

(20) Reece, S. Y.; Nocera, D. G., Annu. Rev. Biochem. 2009, 78, 673-699.

(21) Hammes-Schiffer, S., Acc. Chem. Res. 2009, 42, 1881-1889.

(22) Dempsey, J. L.; Winkler, J. R.; Gray, H. B., Chem. Rev. 2010, 110, 7024-7039.

(23) Warren, J. J.; Tronic, T. A.; Mayer, J. M., Chem. Rev. 2010, 110, 6961-7001.

(24) Hammes-Schiffer, S.; Stuchebrukhov, A. A., Chem. Rev. 2010, 110, 6939-6960.

(25) Hammarström, L.; Styring, S., Energy Environ. Sci. 2011, 4, 2379-2388.

(26) Wenger, O. S., Chem.-Eur. J. 2011, 17, 11692-11702.

(27) Macias-Ruvalcaba, N. A.; Gonzalez, I.; Aguilar-Martinez, M., J. Electrochem. Soc. 2004, 151, E110-E118.

(28) Hankache, J.; Wenger, O. S., Chem. Commun. 2011, 47, 10145-10147.

(29) Hankache, J.; Wenger, O. S., Chem.-Eur. J. 2012, 18, 6443-6447. 
(30) Gupta, N.; Linschitz, H., J. Am. Chem. Soc. 1997, 119, 6384-6391.

(31) Sinnecker, S.; Reijerse, E.; Neese, F.; Lubitz, W., J. Am. Chem. Soc. 2004, 126, 3280-3290.

(32) Huynh, M. H. V.; Meyer, T. J., Chem. Rev. 2007, 107, 5004-5064.

(33) Mecklenburg, S. L.; McCafferty, D. G.; Schoonover, J. R.; Peek, B. M.; Erickson, B. W.; Meyer, T. J., Inorg. Chem. 1994, 33, 2974-2983.

(34) Opperman, K. A.; Mecklenburg, S. L.; Meyer, T. J., Inorg. Chem. 1994, 33, 5295-5301.

(35) Steinberg-Yfrach, G.; Liddell, P. A.; Hung, S. C.; Moore, A. L.; Gust, D.; Moore, T. A., Nature 1997, 385, 239-241.

(36) Lopéz, R.; Leiva, A. M.; Zuloaga, F.; Loeb, B.; Norambuena, E.; Omberg, K. M.; Schoonover, J. R.; Striplin, D.; Devenney, M.; Meyer, T. J., Inorg. Chem. 1999, 38, 2924-2930.

(37) Tkachenko, N. V.; Tauber, A. Y.; Grandell, D.; Hynninen, P. H.; Lemmetyinen, H., J. Phys. Chem. A 1999, 103, 3646-3656.

(38) Frank, R.; Greiner, G.; Rau, H., Phys. Chem. Chem. Phys. 1999, 1, 3481-3490.

(39) Borgström, M.; Johansson, O.; Lomoth, R.; Baudin, H. B.; Wallin, S.; Sun, L. C.; Åkermark, B.; Hammarström, L., Inorg. Chem. 2003, 42, 5173-5184.

(40) Pellegrin, Y.; Forster, R. J.; Keyes, T. E., Inorg. Chim. Acta 2009, 362, 1715-1722.

(41) Lewis, F. D.; Thazhathveetil, A. K.; Zeidan, T. A.; Vura-Weis, J.; Wasielewski, M. R., J. Am. Chem. Soc. 2010, 132, 444-445.

(42) Zhao, X.; Chen, J. P.; Zeng, Y.; Li, Y. Y.; Han, Y. B.; Li, Y., Chin. J. Chem. 2010, 28, 15801586. 
(43) Dupont, N.; Ran, Y. F.; Jia, H. P.; Grilj, J.; Ding, J.; Liu, S. X.; Decurtins, S.; Hauser, A., Inorg. Chem. 2011, 50, 3295-3303.

(44) Hankache, J.; Wenger, O. S., Phys. Chem. Chem. Phys. 2012, 14, 2685-2692.

(45) Malferrari, M.; Francia, F.; Venturoli, G., J. Phys. Chem. B 2011, 115, 14732-14750.

(46) Roundhill, D. M., Photochemistry and Photophysics of Metal Complexes. Plenum Press: New York, 1994.

(47) Balzani, V.; Juris, A.; Venturi, M.; Campagna, S.; Serroni, S., Chem. Rev. 1996, 96, 759-833.

(48) All samples had an optical density (OD) between 0.1 and 0.3 at the excitation wavelength. The emission intensities were corrected for differences in the OD at the excitation wavelength, and they were normalized to a value of 1 at the luminescence band maximum of the reference complexes.

(49) Turro, N. J., Molecular Photochemistry. New York, Amsterdam, 1967.

(50) Marsal, P.; Avilov, I.; da Silva, D. A.; Bredas, J. L.; Beljonne, D., Chem. Phys. Lett. 2004, 392, $521-528$.

(51) Creutz, C.; Chou, M.; Netzel, T. L.; Okumura, M.; Sutin, N., J. Am. Chem. Soc. 1980, 102, 1309-1319.

(52) Schanze, K. S.; MacQueen, D. B.; Perkins, T. A.; Cabana, L. A., Coord. Chem. Rev. 1993, 122, 63-89.

(53) Knight, T. E.; McCusker, J. K., J. Am. Chem. Soc. 2010, 132, 2208-2221.

(54) Walther, M. E.; Wenger, O. S., Dalton Trans. 2008, 6311-6318.

(55) Babaei, A.; Connor, P. A.; McQuillan, A. J.; Umapathy, S., J. Chem. Ed. 1997, 74, 1200-1204.

(56) Ajloo, D.; Yoonesi, B.; Soleymanpour, A., Int. J. Electrochem. Sci. 2010, 5, 459-477. 
(57) Furue, M.; Maruyama, K.; Oguni, T.; Naiki, M.; Kamachi, M., Inorg. Chem. 1992, 31, 37923795.

(58) Walther, M. E.; Wenger, O. S., Inorg. Chem. 2011, 50, 10901-10907.

(59) The spectroelectrochemistry data in Figure 4c was obtained after application of potentials more positive than $0.5 \mathrm{~V}$ vs. $\mathrm{Fc}^{+} / \mathrm{Fc}$ to a $\mathrm{CH}_{2} \mathrm{Cl}_{2}$ solution of the TAA reference molecule shown in the inset, while the spectra in Figure 4d were obtained during application of an electrochemical potential more negative than $-1.2 \mathrm{~V}$ vs. $\mathrm{Fc}^{+} / \mathrm{Fc}$ to a solution of free 9,10 -anthraquinone in $\mathrm{CH}_{2} \mathrm{Cl}_{2}$.

(60) Gutmann, V., Coord. Chem. Rev. 1976, 18, 225-255.

(61) Gurzadyan, G. G.; Steenken, S., Chem. Eur. J. 2001, 7, 1808-1815.

(62) Reichardt, C., Angew. Chem. Int. Ed. 1965, 4, 29-40.

(63) Reichardt, C., Chem. Rev. 1994, 94, 2319-2358.

(64) Lucarini, M.; Mugnaini, V.; Pedulli, G. F.; Guerra, M., J. Am. Chem. Soc. 2003, 125, 8318-8329.

(65) Ahmed, S.; Khan, A. Y.; Qureshi, R.; Subhani, M. S., Russ. J. Electrochem. 2007, 43, 811-819.

(66) In the cyclic voltammograms from Figure 6 there is no evidence for the formation of $\mathrm{AQH}_{2}$. In the spectroelectrochemical experiment we had to apply potentials more negative than $-1.5 \mathrm{~V}$ vs. $\mathrm{Fc}^{+} / \mathrm{Fc}$ for extended periods of time in order to obtain detectable UV-Vis changes. The combination of long electrolysis times with very negative potentials thus seems to favor the formation of $\mathrm{AQH}_{2}$.

(67) Lehmann, M. W.; Evans, D. H., J. Phys. Chem. B 2001, 105, 8877-8884.

(68) Aguilar-Martinez, M.; Macias-Ruvalcaba, N. A.; Bautista-Martinez, J. A.; Gomez, M.; Gonzalez, F. J.; Gonzalez, I., Curr. Org. Chem. 2004, 8, 1721-1738. 
(69) Macias-Ruvalcaba, N. A.; Okumura, N.; Evans, D. H., J. Phys. Chem. B 2006, 110, 2204322047.

(70) Weller, A., Z. Phys. Chem. 1982, 133, 93-98.

(71) Yago, T.; Gohdo, M.; Wakasa, M., J. Phys. Chem. B 2010, 114, 2476-2483.

(72) Kobori, Y.; Yago, T.; Akiyama, K.; Tero-Kubota, S., J. Am. Chem. Soc. 2001, 123, 9722-9723.

(73) Yago, T.; Kobori, Y.; Akiyama, K.; Tero-Kubota, S., J. Phys. Chem. B 2002, 106, 10074-10081.

(74) Yago, T.; Gohdo, M.; Wakasa, M., Chem. Lett. 2009, 38, 880-881.

(75) Bronner, C.; Wenger, O. S., J. Phys. Chem. Lett. 2012, 3, 70-74.

(76) Aoyama, Y.; Asakawa, M.; Matsui, Y.; Ogoshi, H., J. Am. Chem. Soc. 1991, 113, 6233-6240.

(77) Ferreira, K. N.; Iverson, T. M.; Maghlaoui, K.; Barber, J.; Iwata, S., Science 2004, 303, 1831 1838.

(78) Renger, G.; Renger, T., Photosynth. Res. 2008, 98, 53-80.

(79) Lancaster, C. R. D.; Michel, H., Structure 1997, 5, 1339-1359.

(80) Alexov, E. G.; Gunner, M. R., Biochemistry 1999, 38, 8253-8270.

(81) Moore, G. F.; Hambourger, M.; Kodis, G.; Michl, W.; Gust, D.; Moore, T. A.; Moore, A. L., J. Phys. Chem. B 2010, 114, 14450-14457.

(82) Gust, D.; Moore, T. A.; Moore, A. L.; Ma, X. C. C.; Nieman, R. A.; Seely, G. R.; Belford, R. E.; Lewis, J. E., J. Phys. Chem. 1991, 95, 4442-4445.

(83) Moore, G. F.; Hambourger, M.; Gervaldo, M.; Poluektov, O. G.; Rajh, T.; Gust, D.; Moore, T. A.; Moore, A. L., J. Am. Chem. Soc. 2008, 130, 10466-10467. 
(84) Irebo, T.; Reece, S. Y.; Sjödin, M.; Nocera, D. G.; Hammarström, L., J. Am. Chem. Soc. 2007, $129,15462-15464$.

(85) Yuasa, J.; Yamada, S.; Fukuzumi, S., J. Am. Chem. Soc. 2008, 130, 5808-5820.

(86) Kinoshita, I.; Hashimoto, H.; Nishioka, T.; Miyamoto, R.; Kuwamura, N.; Yoshida, Y., Photosynth. Res. 2008, 95, 363-371.

(87) Krejčik, M.; Daněk, M.; Hartl, F., J. Electroanal. Chem. 1991, 317, 179-187.

(88) Wenger, O. S. Acc. Chem. Res. 2011, 44, 25-35.

\section{SYNOPSIS TOC}

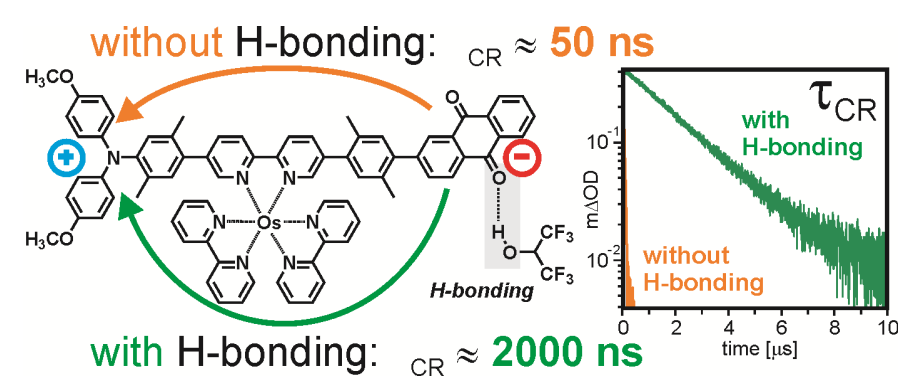

